\author{
Supporting Information
}

\title{
Polymer-Encapsulated Cobalt/Gold Bimetallic Nanoclusters as Stimuli-Responsive Chemiluminescent Nanoprobes for Reactive Oxygen Species
}

\author{
Bingjie. Gao, Mohammad A. Haghighatbin*, and Hua Cui* \\ CAS Key Laboratory of Soft Matter Chemistry, iChEM (Collaborative Innovation Centre of \\ Chemistry for Energy Materials), Department of Chemistry, University of Science and \\ Technology of China, Hefei, Anhui 230026, P. R. China \\ E-mail: hcui@ustc.edu.cn. \\ E-mail:aminhb@ustc.edu.cn
}




\section{Table of Contents}

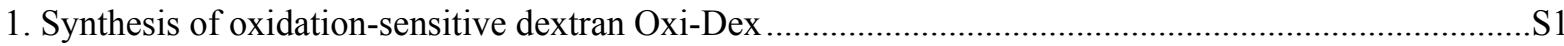

2. FL emission spectra of GSH@Co/Au nanoclusters with different Co:Au molar ratios.............................S2

3. FT-IR spectra of GSH@Co-AuNCs and GSH@Co-AuNCs-ABEI.............................................................S3

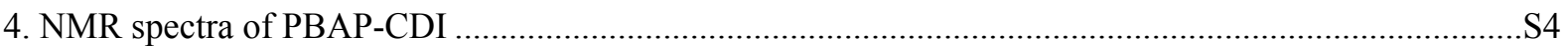

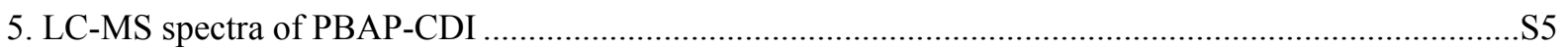

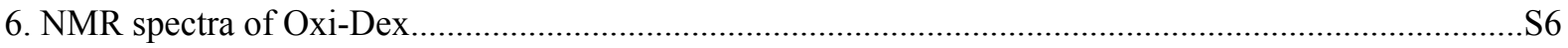

7. UV-vis absorption spectrum of GSH@Co-AuNCs-ABEI, blank Oxi-Dex NPs, and Co-AuNCs-

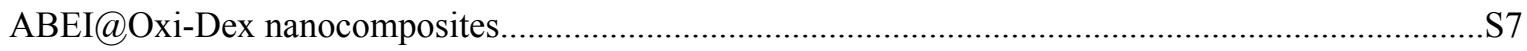

8. FL emission spectra of GSH@Co-AuNCs-ABEI, blank Oxi-Dex NPs, and Co-AuNCs-ABEI@Oxi-Dex

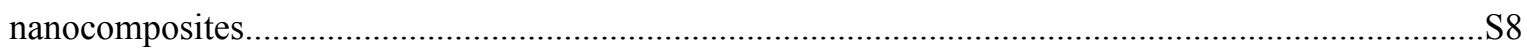

9. Survey XPS of GSH@Co-AuNCs-ABEI, blank Oxi-Dex NPs, and Co-AuNCs-ABEI@Oxi-Dex

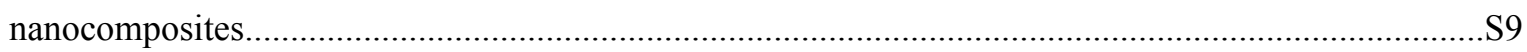

10. Cryo-TEM image of Co-AuNCs-ABEI@Oxi-Dex nanocomposites after ROS stimulation .................S10

11. Comparison of the catalytic effects of GSH@Co/Au nanoclusters with different Co:Au molar ratios on the ABEI- $\mathrm{H}_{2} \mathrm{O}_{2} \mathrm{CL}$ system.

12. Effect of pH of $\mathrm{H}_{2} \mathrm{O}_{2}$ on CL intensity of GSH@Co-AuNCs-ABEI, and Co-AuNCs-ABEI@Oxi-Dex nanocomposites.

13. Stability analysis of Co-AuNCs-ABEI@Oxi-Dex nanocomposites

14. ESR spectra of $\mathrm{O}_{2}{ }^{-}, \mathrm{HO}$, and ${ }^{1} \mathrm{O}_{2}$ spin adducts generated during $\mathrm{CL}$ reaction S14

15. Effect of atmospheres and radical scavengers on CL intensity of Co-AuNCs-ABEI@Oxi-Dex nanocomposites- $\mathrm{H}_{2} \mathrm{O}_{2}$ system

16. Calibration curve of GSH@Co-AuNCs-ABEI for $\mathrm{H}_{2} \mathrm{O}_{2}$ detection

17. Reproducibility of the Co-AuNCs-ABEI@Oxi-Dex nanocomposites CL sensor. $\mathrm{S} 18$

18. Comparison between previously reported non-enzymatic detection methods of $\mathrm{H}_{2} \mathrm{O}_{2}$ 


\section{Synthesis of oxidation-sensitive dextran Oxi-Dex}

Synthesis of PBAP-CDI. The PBAP (5.85 g, $25 \mathrm{mmol})$ and CDI (8.11 g, $50 \mathrm{mmol})$ were dissolved in anhydrous $\mathrm{CH}_{2} \mathrm{Cl}_{2}(30 \mathrm{~mL})$ in a $100 \mathrm{~mL}$ flame-dried three-neck flask. The reaction was stirred at room temperature for $3 \mathrm{~h}$ under the flow of $\mathrm{N}_{2}$. The mixture was diluted in ethyl acetate $(200 \mathrm{~mL})$ and washed with $\mathrm{H}_{2} \mathrm{O}(3 \times 10 \mathrm{~mL})$. The organic phase was washed with brine $(1 \times 10 \mathrm{~mL})$, dried over $\mathrm{MgSO}_{4}$, and concentrated in vacuo to give the pure white PBAP-CDI powder.

Synthesis of Oxi-Dex polymer chains. Dextran ( $\mathrm{Mw}=10000 \mathrm{~g} / \mathrm{mol}, 90 \mathrm{mg}, 0.009 \mathrm{mmol})$ was added to a $10 \mathrm{ml}$ three-neck flask and dissolved in anhydrous DMSO (1.575 mL). DMAP (149.3 mg, $1.22 \mathrm{mmol})$ and PBAP-CDI (364.6 mg, $1.11 \mathrm{mmol})$ were subsequently added to the reaction. The mixture was stirred at room temperature overnight under $\mathrm{N}_{2}$ atmosphere. The modified dextran was then precipitated in $\mathrm{H}_{2} \mathrm{O}(35 \mathrm{~mL})$. The product was isolated by centrifugation at $6000 \mathrm{rpm}$ for $30 \mathrm{~min}$. The resulting precipitate was washed by dispersion in $\mathrm{H}_{2} \mathrm{O}(2 \times 35 \mathrm{~mL})$ followed by centrifugation and removal of the supernatant and lyophilized to obtain the white solid Oxi-Dex polymer chains. The modified dextran was further analyzed and confirmed by ${ }^{1} \mathrm{H}$ NMR. 
2. FL emission spectra of GSH@Co/Au nanoclusters with different Co:Au molar ratios

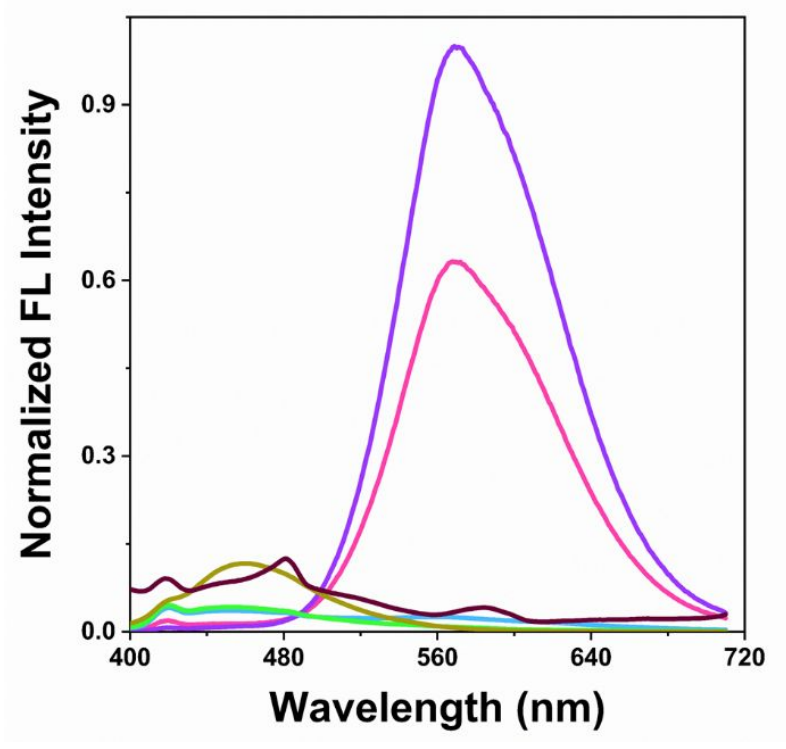

Figure S1. FL emission spectra of GSH@AuNCs (pink), GSH@CoNCs (wine), and GSH@Co/Au bimetallic nanoclusters with different $\mathrm{Co}$ :Au molar ratios (1:80, purple; $1: 20$, blue; $1: 8$, green; 1:4, denoted as GSH@Co-AuNCs, brown), under 365 nm excitation. 
3. FT-IR spectra of GSH@Co-AuNCs and GSH@Co-AuNCs-ABEI

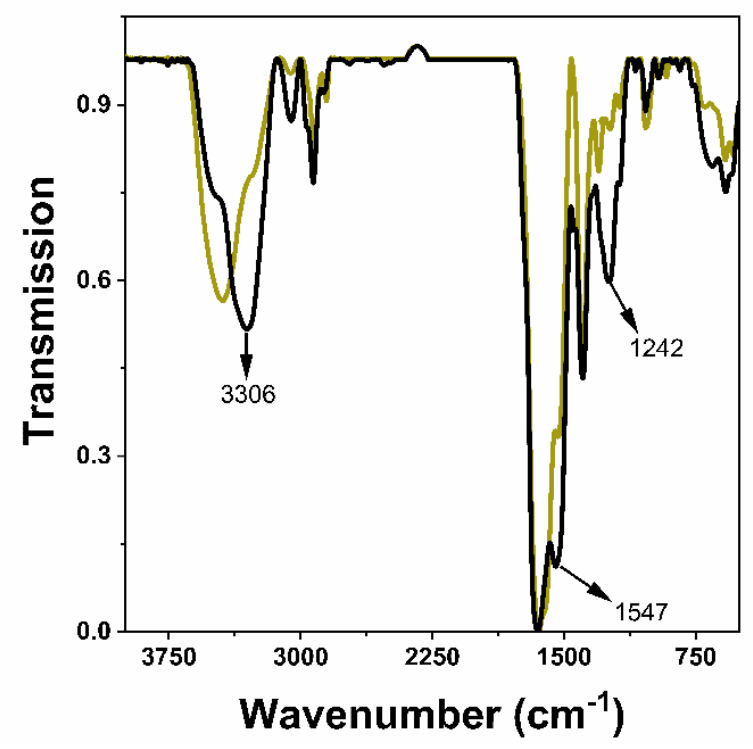

Figure S2. FT-IR spectra of GSH@Co-AuNCs (brown), and GSH@Co-AuNCs-ABEI (black). 


\section{NMR spectra of PBAP-CDI}
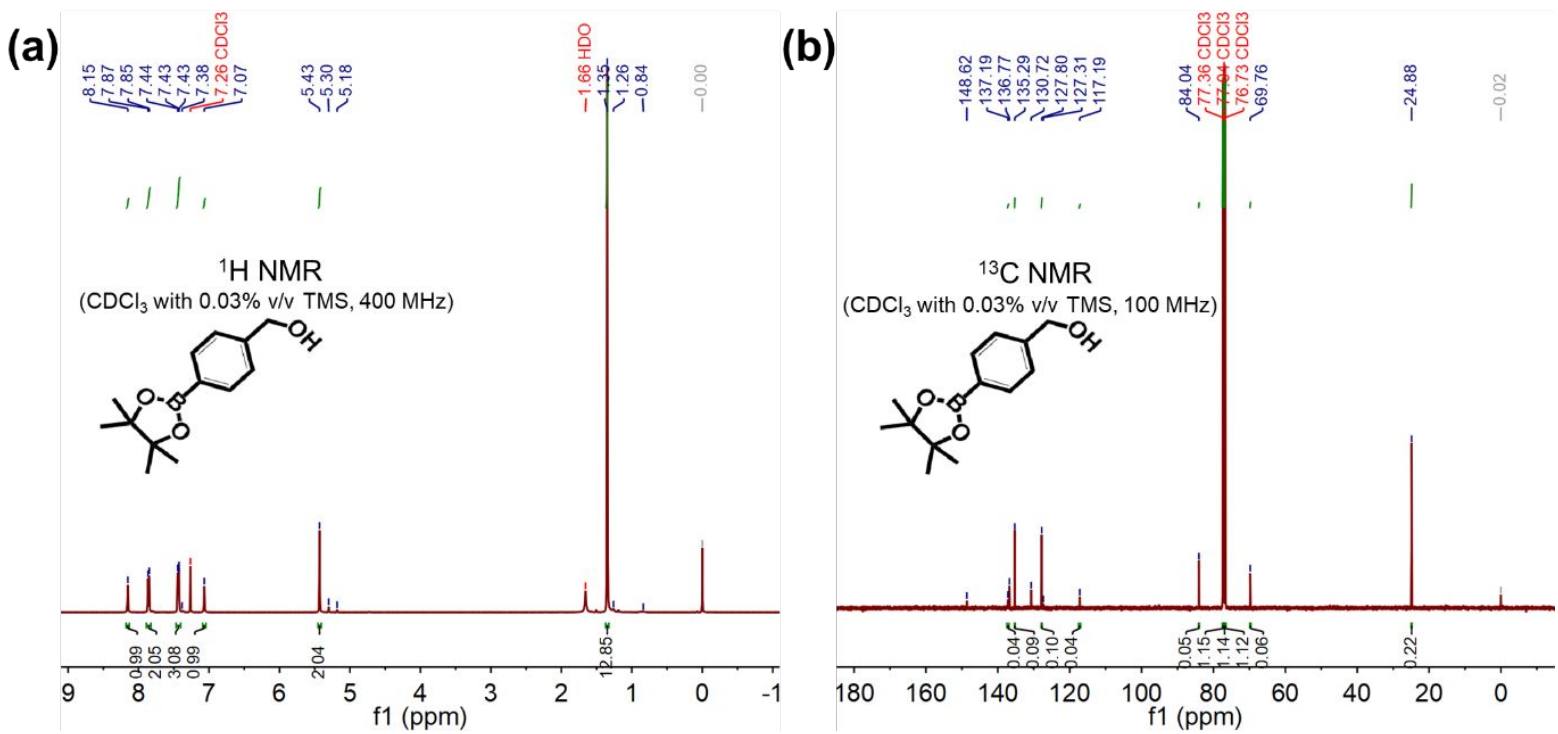

Figure S3. (a) ${ }^{1} \mathrm{H}$ NMR $\left(\mathrm{CDCl}_{3}\right.$ with $0.03 \% \mathrm{v} / \mathrm{v}$ TMS, $\left.400 \mathrm{MHz}\right)$ spectra, and (b) ${ }^{13} \mathrm{C} \mathrm{NMR}\left(\mathrm{CDCl}_{3}\right.$ with $0.03 \% \mathrm{v} / \mathrm{v}$ TMS, $100 \mathrm{MHz})$ spectra of PBAP-CDI. ${ }^{1} \mathrm{H}$ NMR $\delta 1.35(\mathrm{~s}, 12 \mathrm{H}), 5.43(\mathrm{~s}, 2 \mathrm{H}), 7.07(\mathrm{~s}, 1 \mathrm{H}), 7.44$ (m, 3H), $7.85(\mathrm{~d}, 2 \mathrm{H}, J=8.0 \mathrm{~Hz}), 8.15(\mathrm{~s}, 1 \mathrm{H}) ;{ }^{13} \mathrm{C}$ NMR $\delta 24.9,69.8,84.0,117.2,127.8,130.7,135.3,136.8$, 137.2, 148.6. 


\section{LC-MS spectra of PBAP-CDI}

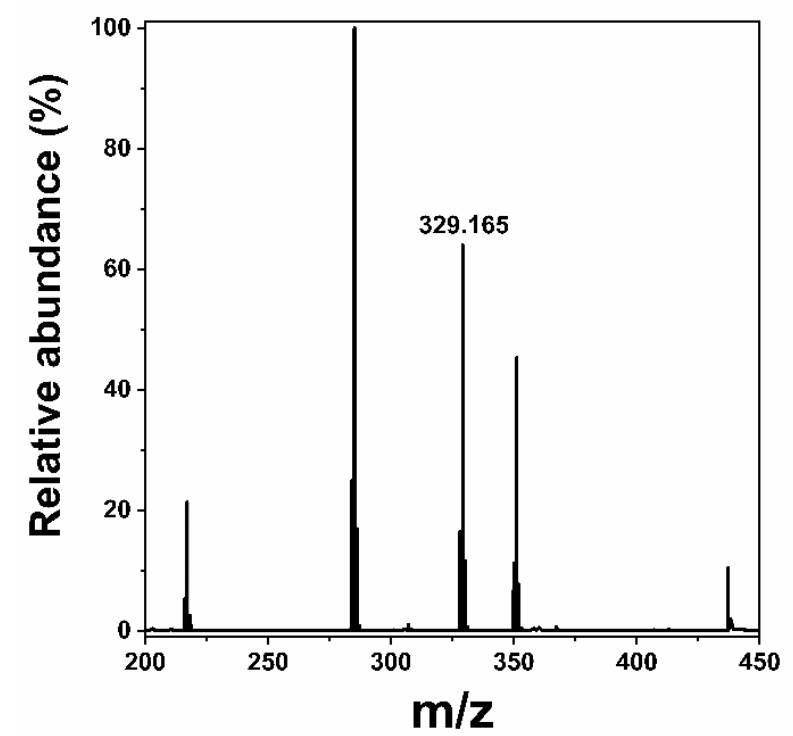

Figure S4. LC-MS spectra of PBAP-CDI. Calculated: $[\mathrm{M}+\mathrm{H}]^{+}\left(\mathrm{C}_{7} \mathrm{H}_{22} \mathrm{O}_{4} \mathrm{~N}_{2}{ }^{11} \mathrm{~B}_{1}\right) m / z=329.167$. Found: [M $+\mathrm{H}]^{+}\left(\mathrm{C}_{7} \mathrm{H}_{22} \mathrm{O}_{4} \mathrm{~N}_{2}{ }^{11} \mathrm{~B}_{1}\right) m / z=329.165$. 


\section{NMR spectra of Oxi-Dex}

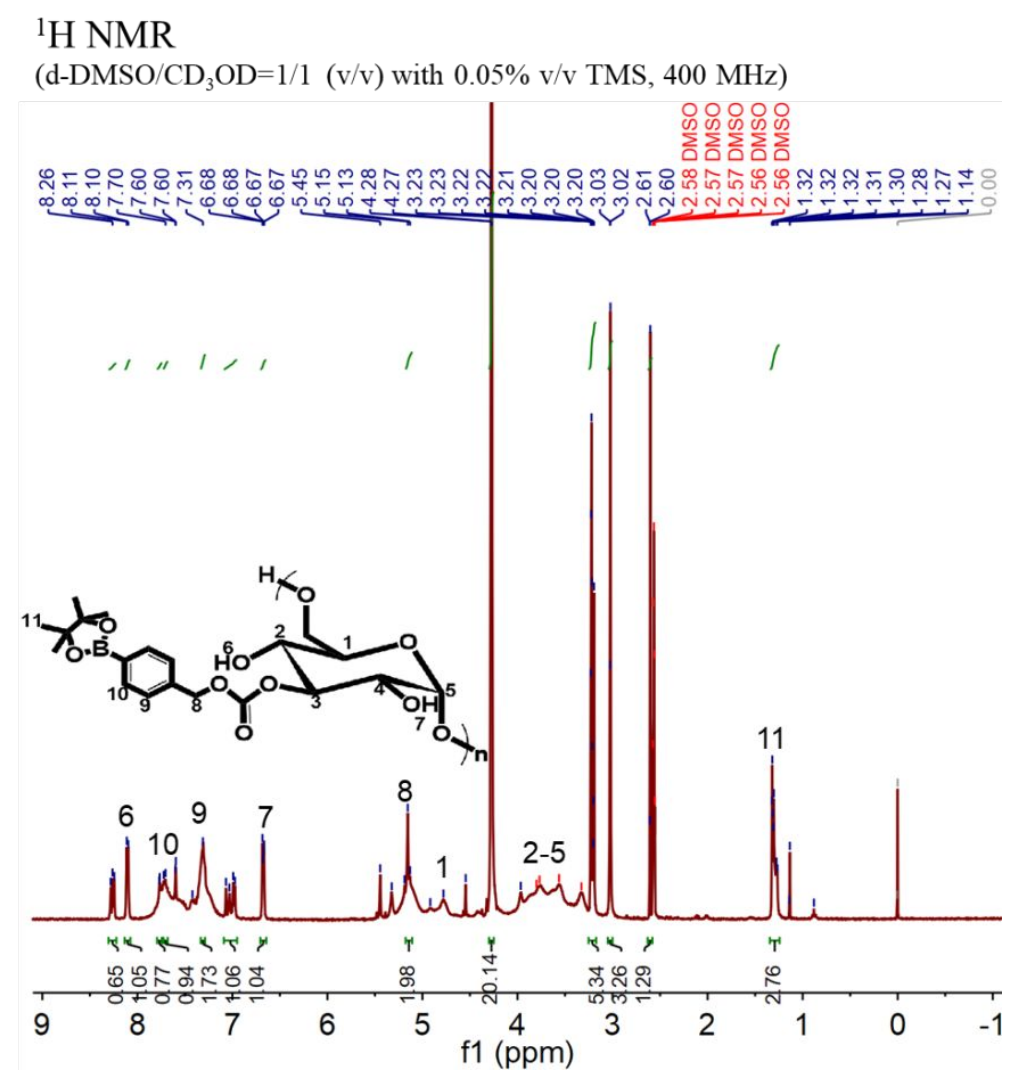

Figure S5. ${ }^{1} \mathrm{H}$ NMR $\left(d-\mathrm{DMSO} / \mathrm{CD}_{3} \mathrm{OD}=1 / 1(\mathrm{v} / \mathrm{v})\right.$ with $0.05 \% \mathrm{v} / \mathrm{v}$ TMS, $\left.400 \mathrm{MHz}\right)$ spectra of Oxi-Dex. 
7. UV-vis absorption spectrum of GSH@Co-AuNCs-ABEI, blank Oxi-Dex NPs, and Co-AuNCs-ABEI@Oxi-Dex nanocomposites

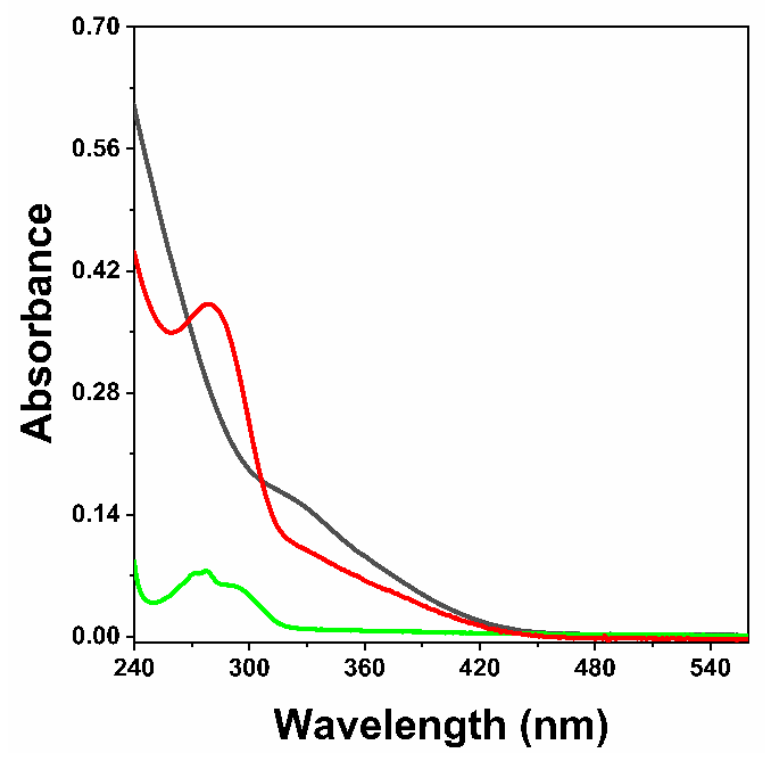

Figure S6. UV-Vis absorption spectrum of GSH@Co-AuNCs-ABEI (black), blank Oxi-Dex NPs (green), and Co-AuNCs-ABEI@Oxi-Dex nanocomposites (red). 
8. FL emission spectra of GSH@Co-AuNCs-ABEI, blank Oxi-Dex NPs, and Co-AuNCs-ABEI@Oxi-Dex nanocomposites

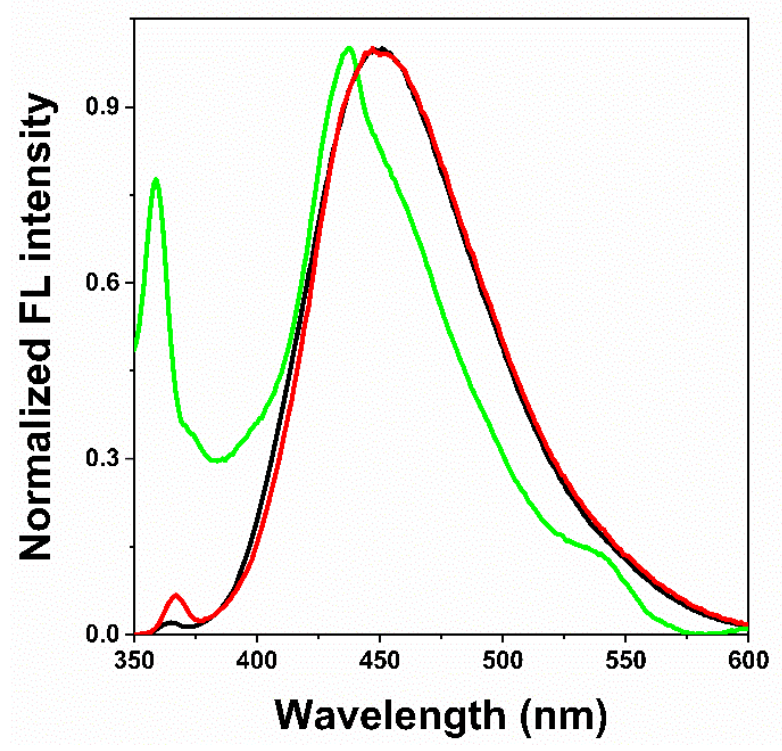

Figure S7. FL emission spectra of GSH@Co-AuNCs-ABEI (black), blank Oxi-Dex NPs (green), and CoAuNCs-ABEI@Oxi-Dex nanocomposites (red), under 320 nm excitation. 
9. Survey XPS of GSH@Co-AuNCs-ABEI, blank Oxi-Dex NPs, and CoAuNCs-ABEI@Oxi-Dex nanocomposites
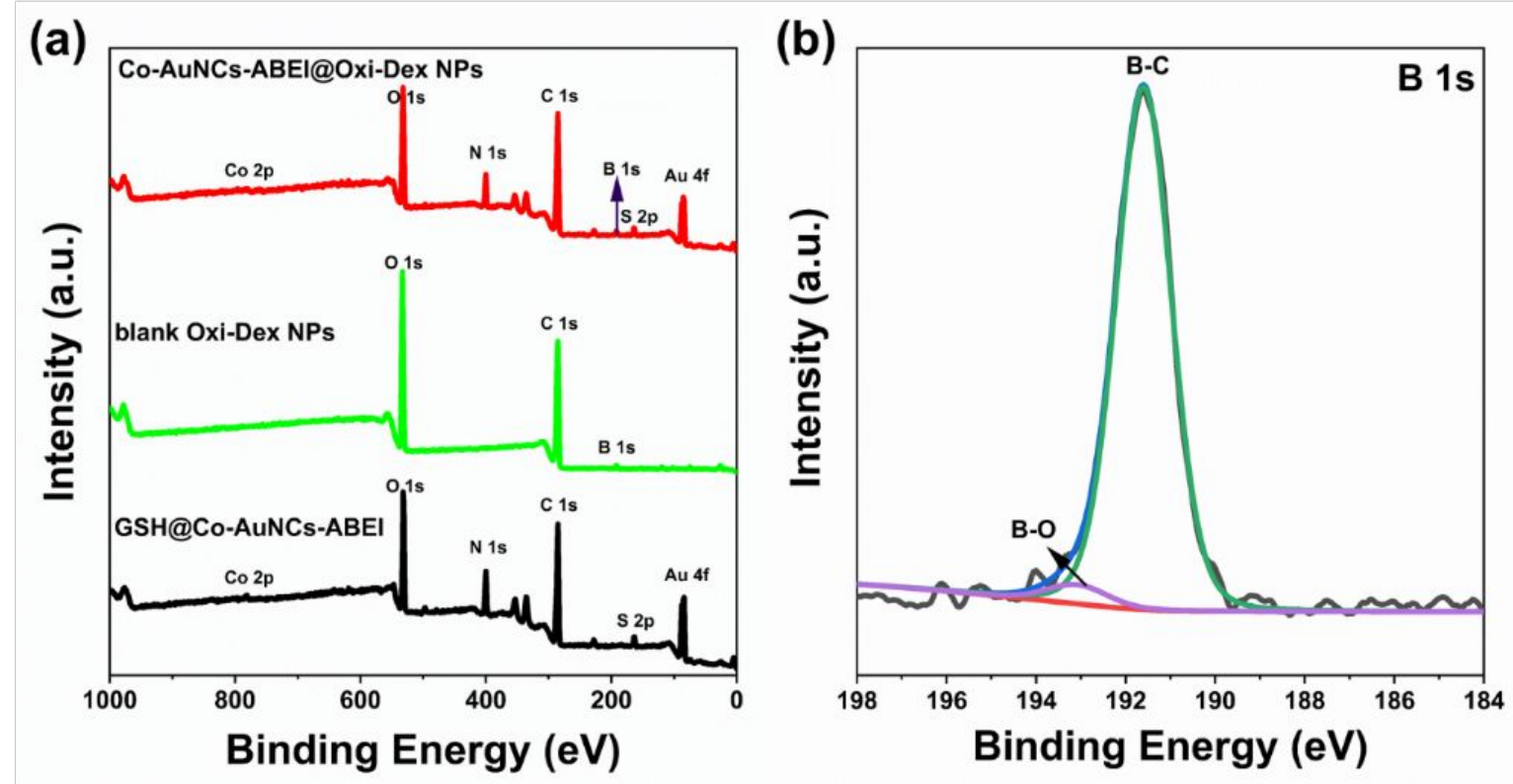

Figure S8. (a) Survey XPS of GSH@Co-AuNCs-ABEI (black), blank Oxi-Dex NPs (green), and CoAuNCs-ABEI@Oxi-Dex nanocomposites (red). (b) The deconvolution of B 1s spectra of Co-AuNCsABEI@Oxi-Dex nanocomposites. 
10. Cryo-TEM image of Co-AuNCs-ABEI@Oxi-Dex nanocomposites after ROS stimulation

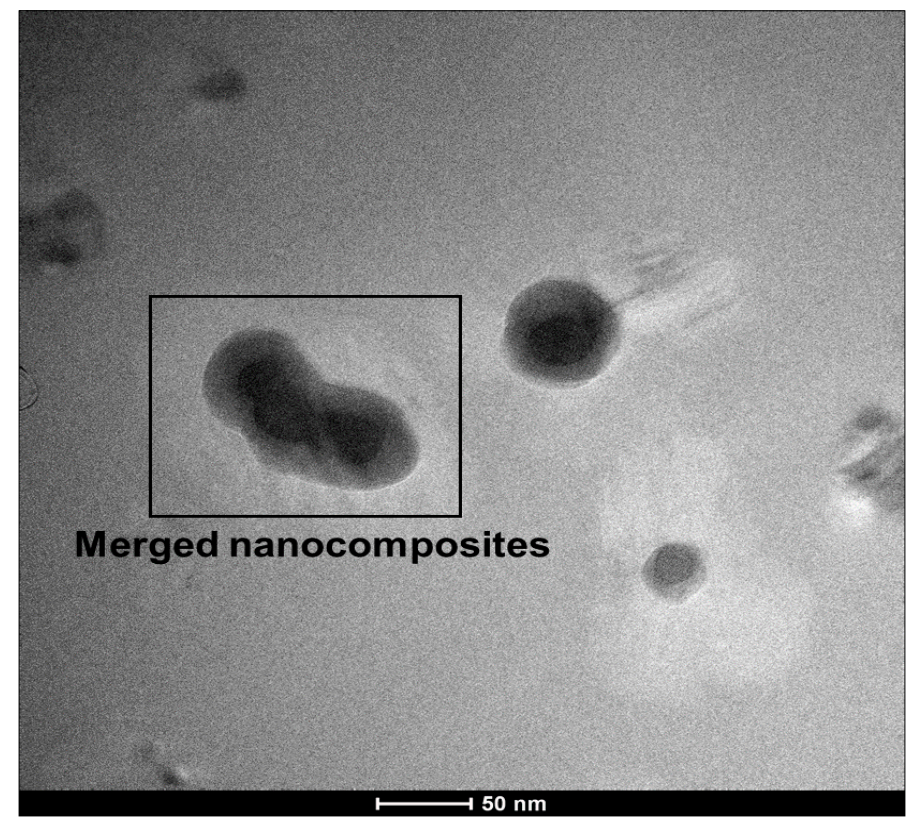

Figure S9. Cryo-TEM image of Co-AuNCs-ABEI@Oxi-Dex nanocomposites in the presence of $1 \mathrm{mM} \mathrm{H}_{2} \mathrm{O}_{2}$, scale bar $=50 \mathrm{~nm}$. 
11. Comparison of the catalytic effects of GSH@Co/Au nanoclusters with different Co:Au molar ratios on the $\mathrm{ABEI}-\mathrm{H}_{2} \mathrm{O}_{2} \mathrm{CL}$ system.

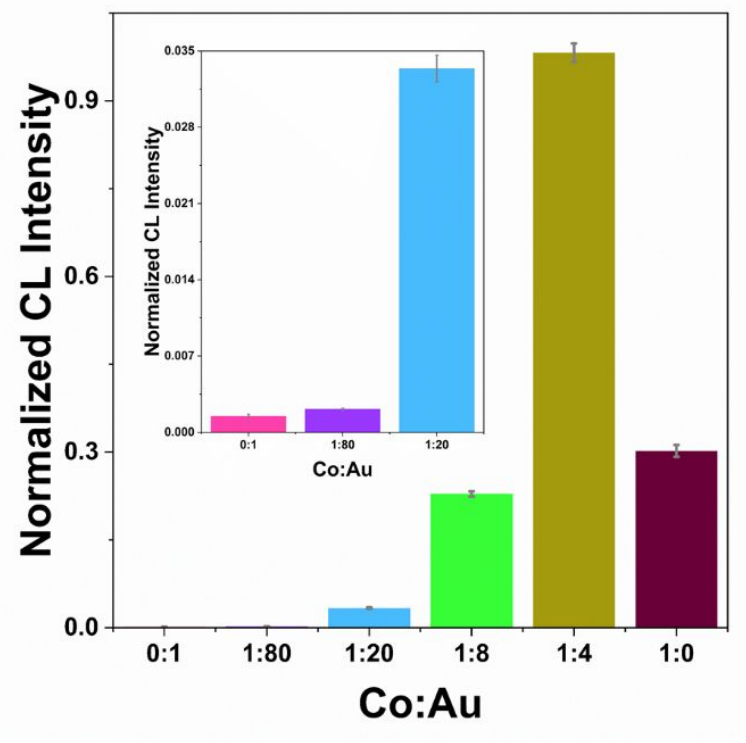

Figure S10. Catalytic effects of GSH@AuNCs (pink), GSH@CoNCs (wine), and GSH@Co/Au bimetallic nanoclusters with different Co:Au molar ratios (1:80, purple; 1:20, blue; 1:8, green; 1:4, denoted as GSH@Co-AuNCs, brown) on the ABEI- $\mathrm{H}_{2} \mathrm{O}_{2} \mathrm{CL}$ system. 


\section{AuNCs-ABEI@Oxi-Dex nanocomposites}

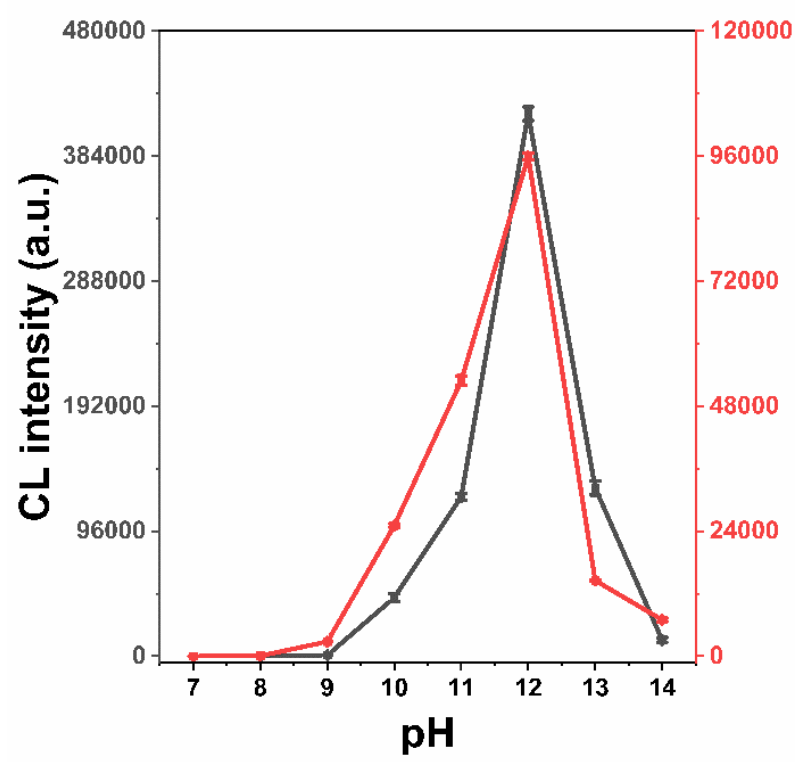

Figure S11. The pH-effect of $\mathrm{H}_{2} \mathrm{O}_{2}$ on the CL intensity of GSH@Co-AuNCs-ABEI (black), and Co-AuNCsABEI@Oxi-Dex nanocomposites (red). Experiment conditions: Under the gain of 1600, $100 \mu \mathrm{L} 1 \mathrm{mM} \mathrm{H}_{2} \mathrm{O}_{2}$ in a solution of B-R buffer ( $\mathrm{pH}$ 6.9-12.1) and $\mathrm{NaOH}(\mathrm{pH} 13.0-14.0)$ was injected into $100 \mu \mathrm{L}$ corresponding material stock solution in a microwell. The integral of CL intensity was recorded within $20 \mathrm{~s}$. 


\section{Stability analysis of Co-AuNCs-ABEI@Oxi-Dex nanocomposites}

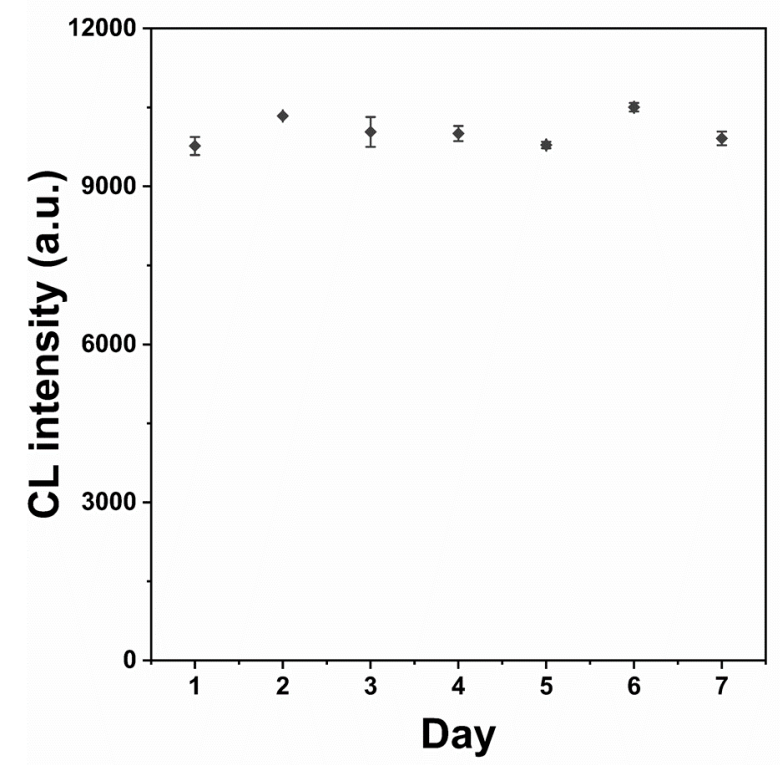

Figure S12. Stability test of Co-AuNCs-ABEI@Oxi-Dex nanocomposites. Daily CL measurements of CoAuNCs-ABEI@Oxi-Dex nanocomposites in a period of 7 days. Experiment conditions: Under the gain of $1600,1 \mathrm{mM} \mathrm{H}_{2} \mathrm{O}_{2}$ in B-R buffer $(80 \mu \mathrm{L}, \mathrm{pH} 12.1)$ was injected into a stock solution of Co-AuNCsABEI@Oxi-Dex nanocomposites $(80 \mu \mathrm{L})$ in a microwell. 


\section{ESR spectra of $\mathrm{O}_{2}{ }^{-}, \mathrm{HO}^{*}$, and ${ }^{1} \mathrm{O}_{2}$ spin adducts generated during $\mathrm{CL}$}

\section{reaction}

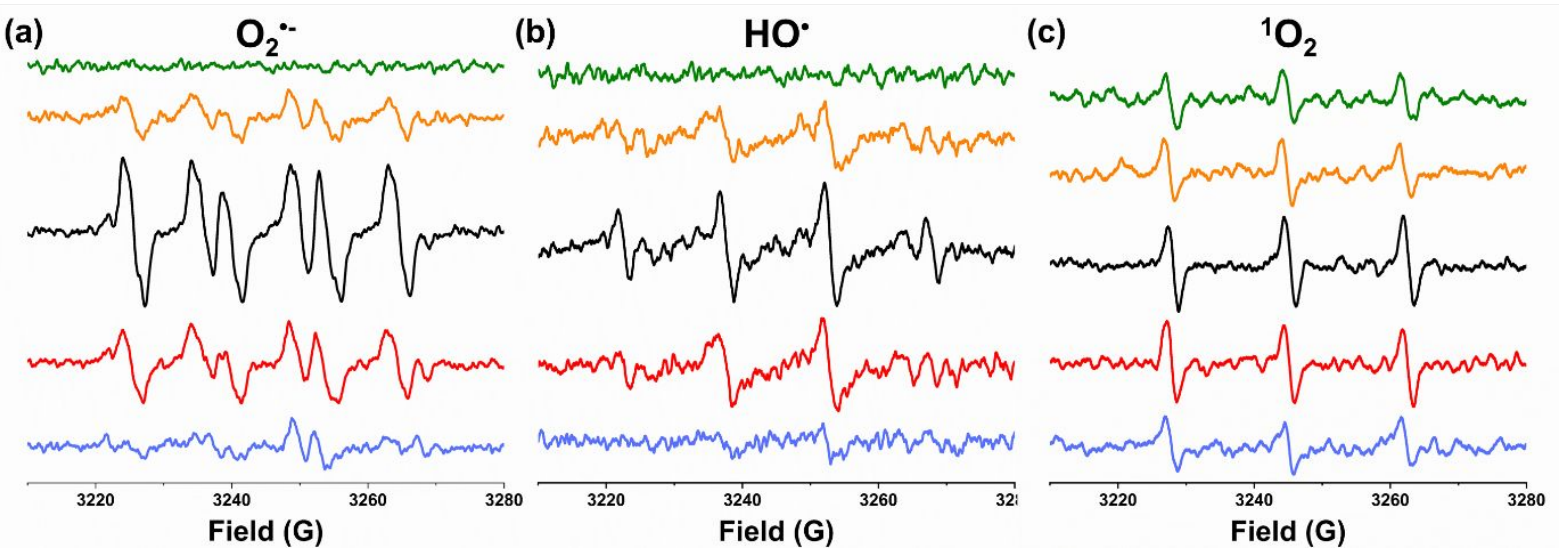

Figure S13. Generation of (a) $\mathrm{O}_{2}{ }^{-}$, (b) $\mathrm{HO}^{*}$, and (c) ${ }^{1} \mathrm{O}_{2}$ spin adducts during the $\mathrm{CL}$ reaction. Control ESR experiments were conducted using spin trap DMPO or TEMP only (olive). Other ESR spectra were obtained from the reactions of GSH@AuNCs-ABEI (orange), GSH@Co-AuNCs-ABEI (black), Co-AuNCsABEI@Oxi-Dex nanocomposites (red), and Co-AuNCs-ABEI@Oxi-Dex nanocomposites in the presence of corresponding radical scavenger (azure) with $\mathrm{H}_{2} \mathrm{O}_{2}$ as well as spin trap, respectively. (a) $\mathrm{O}_{2} \cdots$ : DMPO-OOH adduct in an aqueous solution containing $100 \mathrm{mM} \mathrm{DMPO}$ and $5 \mathrm{mM} \mathrm{H}_{2} \mathrm{O}_{2}$ in the absence and presence of 1 $\mu \mathrm{g} / \mathrm{mL}$ SOD; (b) HO: DMPO-OH adduct in an aqueous solution containing $25 \mathrm{mM}$ DMPO and $5 \mathrm{mM} \mathrm{H}_{2} \mathrm{O}_{2}$ in the absence and presence of $1 \mathrm{mg} / \mathrm{mL}$ thiourea; (c) ${ }^{1} \mathrm{O}_{2}$ : TEMP- ${ }^{1} \mathrm{O}_{2}$ adduct in an aqueous solution containing $25 \mathrm{mM}$ TEMP and $5 \mathrm{mM} \mathrm{H}_{2} \mathrm{O}_{2}$ in the absence and presence of $1 \mathrm{mg} / \mathrm{mL} L$-histidine.

The ESR spectra were applied to verify the generation of three main radical species during the CL reaction between GSH@AuNCs-ABEI, GSH@Co-AuNCs-ABEI, Co-AuNCs-ABEI@Oxi-Dex nanocomposites and $\mathrm{H}_{2} \mathrm{O}_{2}$. 5,5-Dimethyl-1-pyrroline N-Oxide (DMPO, for $\mathrm{O}_{2}{ }^{*-}$ and $\mathrm{HO}$ ) and 2,2,6,6Tetramethyl piperidine (TEMP, for ${ }^{1} \mathrm{O}_{2}$ ) were exploited as spin traps to disclose the production of radicals, and blank sample that only contained DMPO showed no characteristic ESR signal. The ESR signal of $\mathrm{O}_{2}{ }^{--}$ was consist of two components with hyperfine splitting parameters of $\mathrm{a}_{\mathrm{N}}=14.1 \mathrm{G}, \mathrm{a}_{\mathrm{H}}^{\beta_{H}}=13.3 \mathrm{G}$, and $\mathrm{a}_{\mathrm{H}}^{\mathrm{Y}}=$ $1.6 \mathrm{G}$, which was indicative for the DMPO-OOH spin adduct formed between DMPO and $\mathrm{O}_{2}{ }^{\circ}$ (Figure $\mathrm{S} 13 \mathrm{a}$ ). Also, a four-line spectrum with a relative intensity ratio of 1:2:2:1 and hyperfine splitting constants of $a_{N}=$ $\mathrm{a}_{\mathrm{H}}=15.1 \mathrm{G}$ was observed, which was characteristic for the DMPO-OH spin adduct formed between DMPO and $\mathrm{HO}^{*}$ (Figure S13b). Figure S13c demonstrated weak characteristic 1:1:1 triplet line with a hyperfine splitting constant of $\mathrm{a}_{\mathrm{N}}=17.2 \mathrm{G}$, indicating the presence of TEMP- ${ }^{1} \mathrm{O}_{2}$ (TEMPO) spin adduct. However, the ESR intensity involved in the CL reaction remained almost unchanged compared to the blank sample solely containing TEMP. These results indicated that GSH@AuNCs-ABEI, GSH@Co-AuNCs-ABEI, Co-AuNCsABEI@Oxi-Dex nanocomposites have indeed generated $\mathrm{O}_{2}{ }^{-}$and $\mathrm{HO}^{\circ}$, and might have also generated the ${ }^{1} \mathrm{O}_{2}$ during the $\mathrm{CL}$ process. The ESR intensity suggested their activity in producing radicals, namely the catalytic ability to CL, followed the order: GSH@Co-AuNCs-ABEI > Co-AuNCs-ABEI@Oxi-Dex 
nanocomposites > GSH@AuNCs-ABEI.

To identify the contributions of $\mathrm{O}_{2}{ }^{-}, \mathrm{HO}$, and ${ }^{1} \mathrm{O}_{2}$ to the ESR signal, the effect of SOD, thiourea, and $L$-histidine was further investigated, which were specific scavengers for $\mathrm{O}_{2}{ }^{\circ}, \mathrm{HO} \mathrm{HO}^{*}$, and ${ }^{1} \mathrm{O}_{2}$, respectively. When $1 \mu \mathrm{g} / \mathrm{mL}$ SOD or $1 \mathrm{mg} / \mathrm{mL}$ thiourea were added to Co-AuNCs-ABEI@Oxi-Dex nanocomposites, compared with the Co-AuNCs-ABEI@Oxi-Dex nanocomposites without SOD or thiourea, the inhibitory effect was so obvious that the corresponding characteristic ESR signals were almost undetectable. As for the ${ }^{1} \mathrm{O}_{2}$, following a different scenario, the addition of $L$-histidine could not noticeably reduce the characteristic ESR signal of ${ }^{1} \mathrm{O}_{2}$. These results explicitly demonstrated that both $\mathrm{O}_{2}{ }^{\circ}$ and $\mathrm{HO}^{*}$ were the main participants in the $\mathrm{CL}$ reaction, while the ${ }^{1} \mathrm{O}_{2}$ might exhibit a limited contribution to the $\mathrm{CL}$ process. 


\section{Effect of atmospheres and radical scavengers on CL intensity of Co- AuNCs-ABEI@Oxi-Dex nanocomposites- $\mathrm{H}_{2} \mathrm{O}_{2}$ system}
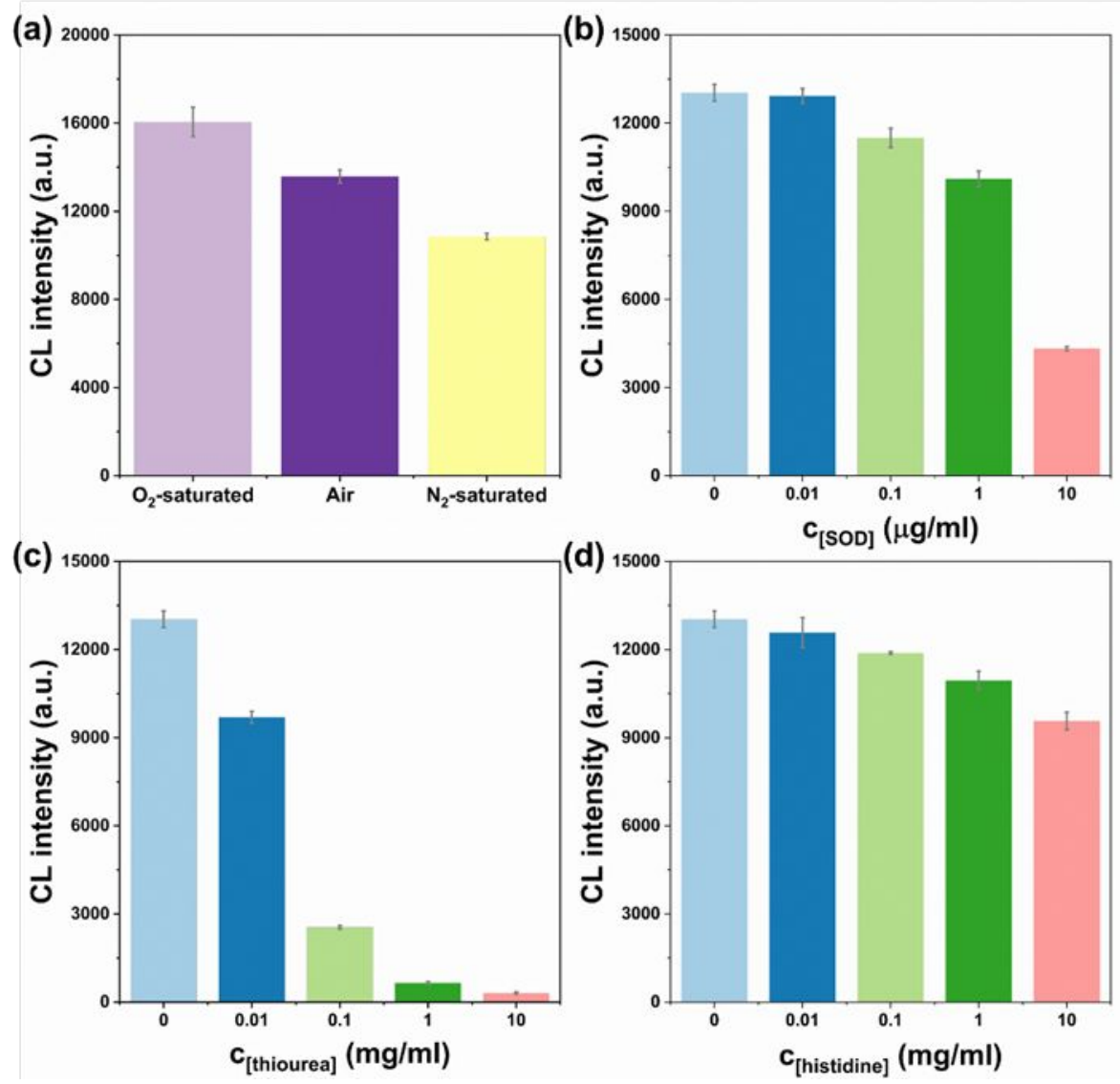

Figure S14. (a) CL kinetic curves of Co-AuNCs-ABEI@Oxi-Dex nanocomposites- $\mathrm{H}_{2} \mathrm{O}_{2}$ under oxygensaturated, air-saturated, and nitrogen-saturated solutions, respectively. (b) CL kinetic curves of Co-AuNCsABEI@Oxi-Dex nanocomposites in the absence and presence of different concentrations of SOD: 0.01 $\mu \mathrm{g} / \mathrm{mL}, 0.10 \mu \mathrm{g} / \mathrm{mL}, 1.0 \mu \mathrm{g} / \mathrm{mL}$, and $10.0 \mu \mathrm{g} / \mathrm{mL}$. (c) CL kinetic curves of Co-AuNCs-ABEI@Oxi-Dex nanocomposites in the absence and presence of different concentrations of thiourea: $0.01 \mathrm{mg} / \mathrm{mL}, 0.1 \mathrm{mg} / \mathrm{mL}$, $1 \mathrm{mg} / \mathrm{mL}$, and $10 \mathrm{mg} / \mathrm{mL}$. (d) CL kinetic curves of Co-AuNCs-ABEI@Oxi-Dex nanocomposites in the absence and presence of different concentrations of $L$-histidine: $0.01 \mathrm{mg} / \mathrm{mL}, 0.1 \mathrm{mg} / \mathrm{mL}, 1 \mathrm{mg} / \mathrm{mL}$, and 10 $\mathrm{mg} / \mathrm{mL}$. Reaction conditions: Under the gain of $1600,100 \mu \mathrm{L} 1 \mathrm{mM} \mathrm{H}_{2} \mathrm{O}_{2}$ in B-R buffer ( $\mathrm{pH}$ 12.1) was injected into $80 \mu \mathrm{L}$ Co-AuNCs-ABEI@Oxi-Dex nanocomposites stock solution mixed with $20 \mu \mathrm{L}$ water or different concentrations of SOD/ thiourea/ $L$-histidine in a microwell. 


\section{Calibration curve of GSH@Co-AuNCs-ABEI for $\mathrm{H}_{2} \mathrm{O}_{2}$ detection}

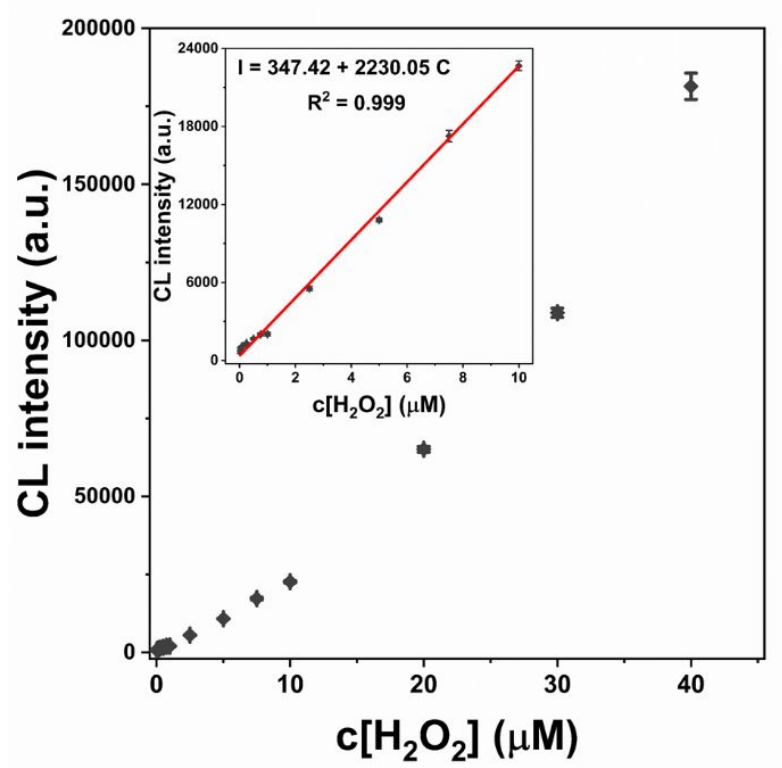

Figure S15. Calibration curve of GSH@Co-AuNCs-ABEI for $\mathrm{H}_{2} \mathrm{O}_{2}$ detection. Reaction conditions: Under the gain of 3600, $90 \mu \mathrm{L}$ B-R buffer (pH 12.1) was injected into $80 \mu \mathrm{L}$ GSH@Co-AuNCs-ABEI solution in a microwell, followed by the introduction of $10 \mu \mathrm{L}$ different concentration of aqueous $\mathrm{H}_{2} \mathrm{O}_{2}$ solutions. 
17. Reproducibility of the Co-AuNCs-ABEI@Oxi-Dex nanocomposites CL sensor
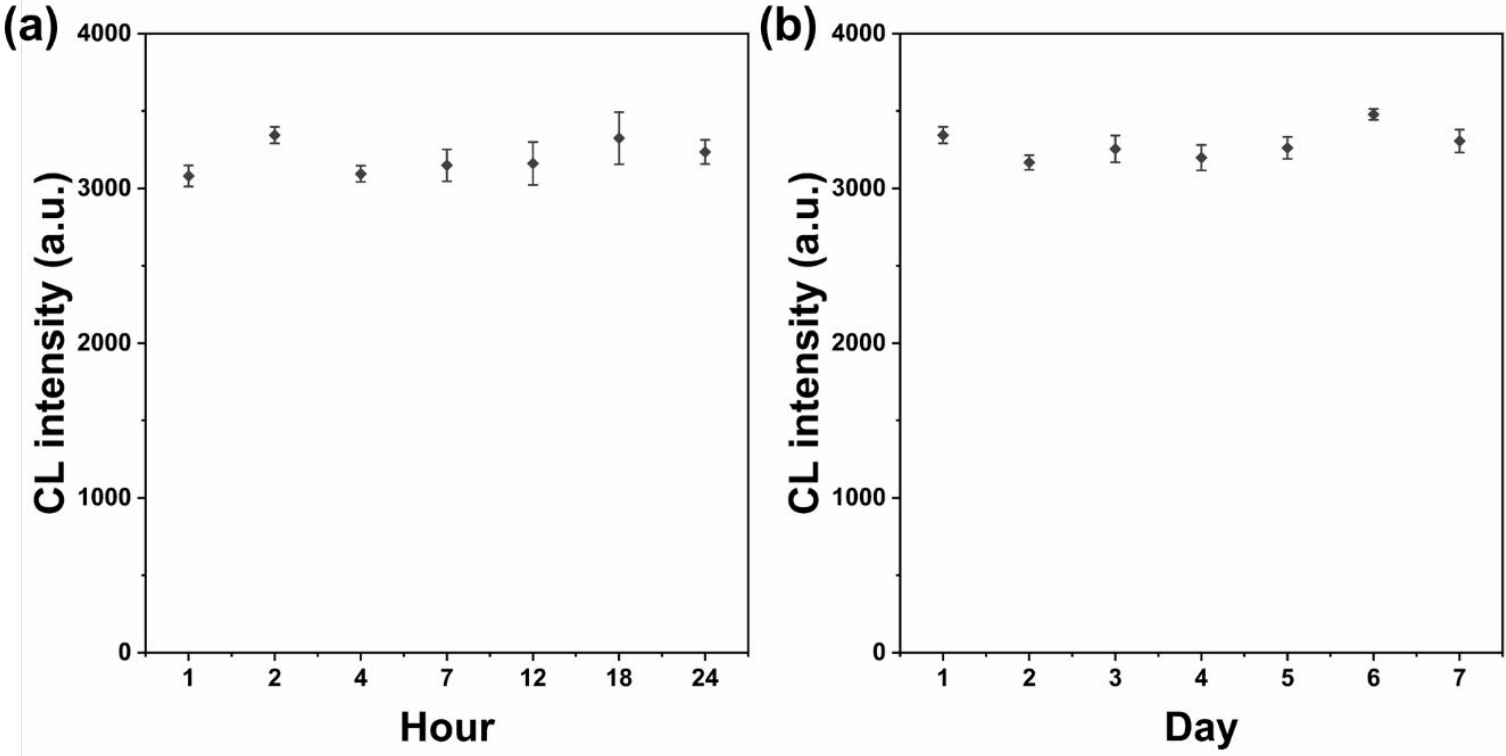

Figure S16. Reproducibility of the proposed Co-AuNCs-ABEI@Oxi-Dex nanocomposites CL sensor for $\mathrm{H}_{2} \mathrm{O}_{2}$ detection (a) in a day and (b) in a week. Reaction conditions: Under the gain of 3600, $90 \mu \mathrm{L}$ B-R buffer (pH 12.1) was injected into $80 \mu \mathrm{L}$ Co-AuNCs-ABEI@Oxi-Dex nanocomposites solution in a microwell, followed by the introduction of $10 \mu \mathrm{L}$ of $10 \mathrm{nM}$ aqueous $\mathrm{H}_{2} \mathrm{O}_{2}$ solution. 


\section{Comparison between previously reported non-enzymatic detection methods of $\mathrm{H}_{2} \mathrm{O}_{2}$}

Table S1. Comparison between previously reported non-enzymatic detection methods of $\mathrm{H}_{2} \mathrm{O}_{2}$.

\begin{tabular}{|c|c|c|c|c|}
\hline Method & Material & Linear range (nM) & $\begin{array}{c}\text { Detection limit } \\
\qquad(\mathbf{n M})\end{array}$ & Ref \\
\hline${ }^{*} \mathbf{E C}$ & CoHCFNPs/GR/CCE & $6.0 \times 10^{2} \sim 3.8 \times 10^{5}$ & $1.0 \times 10^{2}$ & 1 \\
\hline EC & $\mathrm{Fe}_{3} \mathrm{~N}-\mathrm{Co}_{2} \mathrm{~N} / \mathrm{CC}$ & $1.5 \times 10^{2} \sim 8.0 \times 10^{6}$ & 5.9 & 2 \\
\hline EC & $\mathrm{Cu}-\mathrm{MOF} / \mathrm{MPC}-3 / \mathrm{GCE}$ & $1.0 \times 10^{4} \sim 1.2 \times 10^{7}$ & $3.2 \times 10^{3}$ & 3 \\
\hline EC & $\mathrm{Au}-\mathrm{Pd}-\mathrm{Pt} / \mathrm{MoS}_{2}$ & $1.0 \sim 1.0 \times 10^{2}$ & 0.3 & 4 \\
\hline EC & $\mathrm{PtPb} / \mathrm{G}$ & $2.0 \sim 2.5 \times 10^{6}$ & 0.2 & 5 \\
\hline${ }^{*} \mathbf{F L}$ & Eu-MOF & $50.0 \sim 2.0 \times 10^{3}$ & 34.0 & 6 \\
\hline FL & BODIPY Probe & $1.0 \times 10^{2} \sim 4.0 \times 10^{4}$ & 30.0 & 7 \\
\hline${ }^{*} \mathbf{C L}$ & $\mathrm{PtCo}_{\mathrm{x}} /$ Graphene nanocomposites & $0.06 \sim 0.18$ & --- & 8 \\
\hline $\mathbf{C L}$ & $\mathrm{ABEI} / \mathrm{AuNPs} / \mathrm{CoS}_{2} \mathrm{NWs}$ & $1.0 \times 10^{3} \sim 1.0 \times 10^{5}$ & $3.0 \times 10^{2}$ & 9 \\
\hline $\mathbf{C L}$ & Zn/Cu@BSA NCs & $5.0 \sim 1.0 \times 10^{3}$ & 0.3 & 10 \\
\hline $\mathbf{C L}$ & GSH@Co-AuNCs-ABEI & $25.0 \sim 1.0 \times 10^{4}$ & 21.1 & $\begin{array}{l}\text { This } \\
\text { work }\end{array}$ \\
\hline $\mathbf{C L}$ & $\begin{array}{c}\text { Co-AuNCs-ABEI@Oxi-Dex } \\
\text { nanocomposites }\end{array}$ & $0.05 \sim 100$ & 0.036 & $\begin{array}{l}\text { This } \\
\text { work }\end{array}$ \\
\hline
\end{tabular}

EC: electrochemistry; FL: fluorescence; CL: chemiluminescence. 


\section{References}

(1) Yang, S.; Li, G.; Wang, G.; Zhao, J.; Hu, M.; Qu, L., A novel nonenzymatic $\mathrm{H}_{2} \mathrm{O}_{2}$ sensor based on cobalt hexacyanoferrate nanoparticles and graphene composite modified electrode. Sens. Actuators, B 2015, 208, 593-599.

(2) Zhou, D.; Cao, X.; Wang, Z.; Hao, S.; Hou, X.; Qu, F.; Du, G.; Asiri, A. M.; Zheng, C.; Sun, X., Fe $_{3} \mathrm{~N}-$ $\mathrm{Co}_{2} \mathrm{~N}$ Nanowires Array: A Non-Noble-Metal Bifunctional Catalyst Electrode for High-Performance Glucose Oxidation and $\mathrm{H}_{2} \mathrm{O}_{2}$ Reduction toward Non-Enzymatic Sensing Applications. Chemistry 2017, 23, 52145218.

(3) Zhang, Y.; Bo, X.; Luhana, C.; Wang, H.; Li, M.; Guo, L., Facile synthesis of a Cu-based MOF confined in macroporous carbon hybrid material with enhanced electrocatalytic ability. Chem. Commun. 2013, 49, 6885-6887.

(4) Dou, B.; Yang, J.; Yuan, R.; Xiang, Y., Trimetallic Hybrid Nanoflower-Decorated $\mathrm{MoS}_{2}$ Nanosheet Sensor for Direct in Situ Monitoring of $\mathrm{H}_{2} \mathrm{O}_{2}$ Secreted from Live Cancer Cells. Anal. Chem. 2018, 90, 59455950.

(5) Sun, Y.; Luo, M.; Meng, X.; Xiang, J.; Wang, L.; Ren, Q.; Guo, S., Graphene/Intermetallic PtPb Nanoplates Composites for Boosting Electrochemical Detection of $\mathrm{H}_{2} \mathrm{O}_{2}$ Released from Cells. Anal. Chem. 2017, 89, 3761-3767.

(6) Cui, Y.; Chen, F.; Yin, X. B., A ratiometric fluorescence platform based on boric-acid-functional EuMOF for sensitive detection of $\mathrm{H}_{2} \mathrm{O}_{2}$ and glucose. Biosens. Bioelectron. 2019, 135, 208-215.

(7) Xu, J.; Li, Q.; Yue, Y.; Guo, Y.; Shao, S., A water-soluble BODIPY derivative as a highly selective "Turn-On" fluorescent sensor for $\mathrm{H}_{2} \mathrm{O}_{2}$ sensing in vivo. Biosens. Bioelectron. 2014, 56, 58-63.

(8) Yang, P.; Jin, S. Y.; Xu, Q. Z.; Yu, S. H., Decorating PtCo bimetallic alloy nanoparticles on graphene as sensors for glucose detection by catalyzing luminol chemiluminescence. Small 2013, 9, 199-204.

(9) Zhu, Q.; Huang, J.; Yan, M.; Ye, J.; Wang, D.; Lu, Q.; Yang, X., N-(Aminobutyl)-N-(ethylisoluminol)functionalized gold nanoparticles on cobalt disulfide nanowire hybrids for the non-enzymatic chemiluminescence detection of $\mathrm{H}_{2} \mathrm{O}_{2}$. Nanoscale 2018, 10, 14847-14851.

(10) Chen, H.; Lin, L.; Li, H.; Li, J.; Lin, J.-M., Aggregation-Induced Structure Transition of ProteinStabilized Zinc/Copper Nanoclusters for Amplified Chemiluminescence. ACS Nano 2015, 9, 2173-2183. 